\title{
Screening Camelia sinensis Germplasm Against Grey Leaf Blight of Tea
}

\author{
Asma Akbar, Farrukh Hamid \& Sonia Sumreen \\ National Tea and High Value Crops Research Institute, Shinkiare, Mansehra, Pakistan
}

\section{Gul Shad Ali \& Brian Pearson}

Mid-Florida Research and Education Center, and Department of Plant Pathology, University of Florida/Institute of Food and Agricultural Sciences, 2725 Binion Rd, Apopka, FL 32703

Received: October 15, 2017 Accepted: October 30, 2017 Published: November 17, 2017

doi:10.5296/jas.v5i4.11991

URL: https://doi.org/10.5296/jas.v5i4.11991

\begin{abstract}
Grey blight is a foliar disease of tea plants (Camellia sinensis) caused by Pestalotiopsis. The grey blight pathogen was isolated from infected leaves of tea plants in the National Tea and High Value Crop Research Institute (NTHRI), Shinkiari, Khyber Pakhtunkhwa, Pakistan. Eight different varieties, Indonesian, Roupi, Jue King, P-5, P-3, Qi man, Chuy and P-1, were investigated for yield loss and resistance against the grey blight disease. All varieties displayed considerably different levels of resistance to Pestalotiopsis ( $p<0.05)$. The most resistant variety was Indonesian, which showed the lowest number of lesions (1.5 leaf $\left.{ }^{-1}\right)$ and the smallest lesion diameter $(3.0 \mathrm{~cm})$, whereas the most susceptible variety was P-1 which showed the highest number of lesions $\left(3.83\right.$ leaf $\left.^{-1}\right)$ and the largest lesion diameter $(15.0 \mathrm{~cm})$. The grey leaf blight pathogen significantly affected biomass and dry matter of the tested varieties. Compared to non-inoculated control, inoculation with Pestalotiopsis reduced the number of leaves by $40 \%(p<0.05)$, fresh leaf weight by $31 \%(p<0.05)$ and dry leaf weight by $59 \%(p<0.05)$. Whereas, the Indonesian variety was the least affected showing only $11 \%$ $(p<0.05), 19 \%(p<0.05)$, and $28 \%(p<0.05)$ reduction in number of leaves, fresh weight and dry weight, respectively, over control. These results showed that Pestalotiopsis significantly reduced tea yield and that this disease can be managed by growing resistant varieties.
\end{abstract}

Keywords: Pestalotiopsis, Grey leaf blight, Tea, Disease Resistance

\section{Introduction}

Tea (Camellia sinensis (L.) O. Kuntze) is a high-value evergreen tree that is primarily grown for its caffeine-rich leaves. The average height of tea trees is $10-15 \mathrm{~m}$, but for easier picking 
of the leaves, it is pruned back to between $0.5 \mathrm{~m}$ and $1.5 \mathrm{~m}$ in tea plantations. Various kinds of tea varieties are grown in the world but the most important ones are the China type $(C$. sinensis var sinensis) and Assam type ( $C$. sinensis var assamica). Tea is adapted to high altitudes in tropical or low-lands in subtropical regions of the world with an average air temperature between $18-30^{\circ} \mathrm{C}$. Well drained acidic soils with $\mathrm{pH} 4.5-5.0$, full sunshine and adequate rainfall (1500-2000 mm per annum) are optical conditions for good production. World tea production was 5.07 million tonnes in 2013, with Asian countries as the predominant producers, accounting for approximately $85 \%$ of total world production, followed by Africa (13\%) and Latin America (2\%) (Food and Agriculture Organization of the United Nations, 2015).

Tea is considered the second most important beverage consumed worldwide (Henderson et al., 2002). Tea is mostly consumed either as black tea or green tea, but with the advancement of manufacturing processes, tea is now consumed as fermented black tea, non-fermented green tea and semi-fermented oolong tea. Tea plays an important role in supplying antioxidants, which help prevent chronic diseases (Naska et al., 2000). It contains polyphenols and other metabolites, with anti-carcinoma (Wang and Bachrach, 2002; Zhang et al., 2012), anti-oxidative (Rietveld and Wiseman, 2003; Fatima and Rizvi, 2015) and anti-arteriosclerosis (Lee et al., 2015) properties. These polyphenols are also reported to be effective for the prevention of Alzheimer's and Parkinson diseases (Mandel, Amit, Weinreb, Reznichenko, and Youdim, 2008; Anandhan, Tamilselvam, Radhiga, Rao, and Essa, 2012) and for their anti-obesity effects in human and animals (Zhong, Furne, and Levitt, 2006; Ashigai et al., 2016).

Pakistan ranks seventh on the list of tea-consuming countries. However, due to limited tea cultivation, it is the third largest importer of tea in the world, spending valuable capital on tea importation. In order to meet tea demand and to reduce tea importation, limited-scale trial plantations have been established in northern areas of Khyber Pakhtunkhwa province, which offers suitable conditions for tea cultivation. Optimal conditions for tea cultivation are also found in several other adjacent areas in the Himalayas such as Chitral, Battagram and Besham. Currently there is very limited knowledge about cultivation and any unforeseen agronomic issues that could arise due to biotic and abiotic stresses in Pakistan. In particular, very little is known about pests and diseases of tea that could severely hinder the large scale establishment of tea plantations.

There are many bacterial, fungal and nematode diseases which attack tea plants and cause huge losses in other parts of the world where tea is grown (Keith, Ko, \& Sato, 2006). Some of the most common diseases that affect tea quality and quantity include grey blight (Pestalotiopsis), brown blight (Colletotrichum), blister blight (Exobasidium vexans), leaf spots (Cylindrocladium, Calonectria, Chochliobolus) and red rust (Cephaleuros virescens) (Chen, Zeng, Shu, Wang, \& Tong, 2017). Currently there are no reports of any of these diseases in tea plantations in Pakistan. The purpose of this study was to find out occurrences of any of these potentially damaging diseases in the tea gardens of Pakistan. Preliminary surveys indicated the occurrence of unidentified spots on the leaves and stalks of numerous tea plants. To find out what factors may be involved in the etiology of these spots, this study 
was conducted with the following objectives: 1) Detection and incidence of leaf blight of tea in potential tea growing areas of Pakistan, and 2) Screening of the local and imported tea cultivars against the identified pathogen for resistance. Here we report for the first time the occurrence of grey blight caused by Pestalotiopsis on tea in Pakistan. Grey leaf blight is one of the most damaging tea diseases, causing up to a 10-20\% loss in production (Koh, Shin, and Hun, 2001; Keith et al., 2006). This disease generally affects young shoots, bare stalks and mature foliage, and is primarily managed using fungicides (Sanjay and Baby, 2005). For long-term and environmentally friendly management of this disease, finding and deploying resistant varieties, specifically for organic tea production, is highly desirable. In this study we also report that tea varieties grown in Pakistan display varying levels of resistance to Pestalotiopsis, with some varieties displaying strong resistance. This information is useful for future breeding efforts to produce Pestaloltiopsis resistant tea varieties. Results reported here provide essential information for planning outreach and control options for the management of grey leaf spot.

\section{Materials and Methods}

\subsection{Survey and Isolation of the Pathogen}

A detailed survey was carried out in all tea growing areas including the National Tea and High Value Crops Research Institute (NTHRI), Shinkiari, Mansehra. Leaf samples showing symptoms were collected and the pathogen was isolated as follows. The infected leaves were washed under running tap water and then rinsed with distilled water. Leaves were surface sterilized with $0.1 \%$ mercuric chloride for 1 minute, rinsed thoroughly with distilled water three times and blotted dry with sterilized filter papers. The leaves were cut into small pieces and placed on Potato Dextrose Agar (PDA) plates. The plates were incubated for 7-10 days at $25^{\circ} \mathrm{C}$ and the growing mycelial tips were aseptically transferred to new PDA plates for further purification. The pure culture of the pathogen was stored in PDA slants at $4{ }^{\circ} \mathrm{C}$ (Pallavi et al., 2012).

\subsection{Pathogen Identification}

For the identification of the pathogen, culture morphology, conidial morphology and growth rate of the fungus was observed from 7 to 12 days old culture grown on PDA plates. For this purpose, basic mycological key was used. Mycelium color, orientation, spore structure and size were noted. The shape, length and width of the conidia were determined under microscope and mean length and width of the conidia were calculated according to the method of Maharachchikumbura et al., 2013.

\subsection{In vivo Determination of Pathogenicity and Screening of Cultivars}

To confirm the pathogenicity and to find out grey leaf resistant tea varieties, a detailed experiment was designed at NTHRI Shinkiari Mansehra, Khyber Pakhtunkhwa, Pakistan. Virulence of the pathogen was tested under greenhouse condition on eight different varieties: Indonesian, Roupi, Jue King, P-5, P-3, Qi man, Chuy and P-1. Spore suspension was made by adding sterile distilled water to the mycelium and the concentration of spores in suspension was measured through haemocytometer $\left(2 \times 10^{6}\right.$ spore $\left.\mathrm{mL}^{-1}\right)$. Fully expanded 
healthy leaves of the same age were wounded $(3 \mathrm{~mm})$ with a sterile scalpel and artificially inoculated with spore suspension of Pestalotiopsis (Chen and Zhu, 2011). Four leaves per treatment were inoculated for each variety. Ten days after inoculation, diameters of lesions were measured. Plants without inoculation served as control. Based on the size of the lesion, varieties were categorized as susceptible $(\geq 11 \mathrm{~mm})$, moderately resistant $(7-10 \mathrm{~mm})$ and resistant ( $\leq 5 \mathrm{~mm}$ ) (Takeda, 2002). Data regarding number of leaves plant ${ }^{-1}$, fresh and dry leaf weight and dry leaf weight plant $^{-1}$ were also recorded.

\subsection{Statistical Analysis}

Experiments were conducted using a randomized complete block design in a split-plot arrangement with pathogen inoculation as the main plot (inoculated and non-inoculated) and varieties in subplot. Data were analysed using analysis of variance (ANOVA) using STATISTIX software (8.1) (Analytical Software, Tallahassee, FL, USA). The mean variance was analysed using a least significant difference (LSD) test at 0.05 probability level.

\section{Results and Discussion}

\subsection{Symptomatology}

Small, yellow oval shaped lesions first appeared on the inoculated leaf area, which turned brown with time and developed black dots arranged in concentric rings. Lesions were surrounded by yellow halo. These symptoms are consistent with the symptoms caused by Pestalotiopsis on tea (Chen, Zeng, Shu, Wang, \& Tong, 2017; Keith et al., 2006). At the advanced stage of the disease, the middle of the infected area dried and fell off, giving the leaves shot hole appearance.

\subsection{Isolation and Identification of the Pathogen}

Putative pathogen was isolated from infected leaves on PDA plates. Three to five days after culture on PDA, hyphae emerged from margins of leaf segments. After transfer to fresh potato dextrose agar (PDA) medium, these hyphae developed into colonies showing white to whitish pink patterns from the edge to the center of the colony, which turned darker with age. Approximately seven days after incubation, black acervuli formed in roughly concentric rings close to the margins of plates. Conidia were fusiform, straight and some were slightly curved, each with four septa dividing each conidium into five cells. The basal and apical cells were hyaline with transparent thin and smooth walls, whereas the middle cells were dark tan color. Two to three apical appendages, rising from the upper end of the apical cell, were tubular and slightly swollen at the apex. Basal appendages were mostly filiform and sometimes knob shaped (Figure 1B). These conidial characteristics are agreement with those of Pestalotiopsis reported earlier by Maharachchikumbura et al. 2013. 


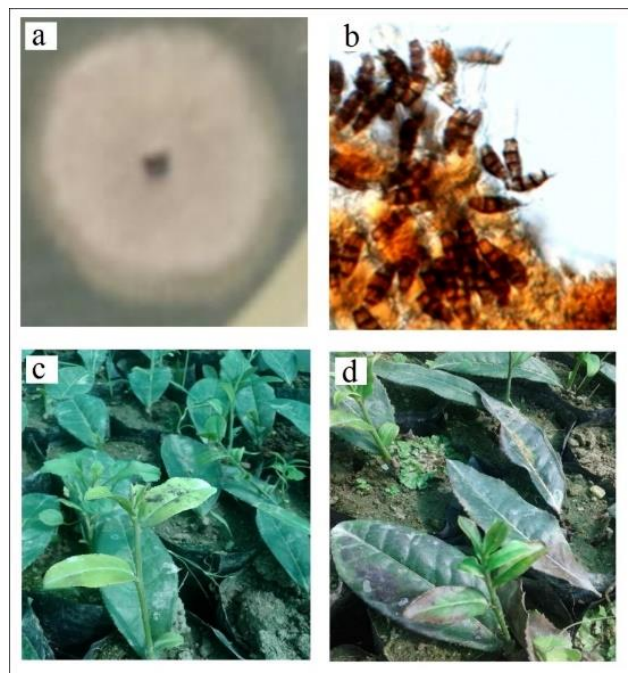

Figure 1. Pestalotiopsis the causal organism of grey blight of tea plant. $\mathrm{A}=$ Colony in culture; $\mathrm{B}=$ Conidia in culture $\mathrm{C}=$ Control treatment $\mathrm{D}=$ Grey Blight symptoms on leaves of Camellia sinensis.

\subsection{Pathogenicity Tests}

Pathogenicity of the fungus was confirmed by inoculating eight different tea varieties -Indonesian, Roupi, Jue King, P-5, P-3, Qi man, Chuy and P-1 - in a greenhouse. Inoculated leaves started to appear as drying at the leaf edge after 72 hours of inoculation. These lesions continued to grow rapidly over time (Figure 1D). The control plant was sprayed only with distilled water and did not show any symptoms (Figure 1C). The pathogen was re-isolated and grown on PDA, and confirmed to be Pestalotiopsis fulfilling Koch' postulates. These experiments were repeated three times. These results indicated that Pestalotiopsis was responsible for the grey blight of the tea plant in NTHRI, Shinkiyari Manhesra, Pakistan.

\subsection{Varietal Screening for Resistance to Pestalotiopsis}

Growing disease-resistant tea varieties is the most sustainable and environmentally friendly method for controlling grey blight of tea. In order to find resistance to this disease, we screened eight different tea varieties that are grown in Pakistan using artificial inoculation. All cultivars displayed significant differences in number of lesions per leaf and lesion sizes $(p<0.05)$. The highest number of lesions per leaf (3.83) were observed on variety $\mathrm{P} 1$, whereas the least number of lesions per leaf (1.5) were observed on the Indonesian variety (Table 1). Similarly, the largest and smallest lesion sizes were observed on variety P1 and Indonesian, respectively (Table 1). The rest of the varieties displayed variable numbers and sizes of lesions. Non-inoculated control did not display any lesions. Based on lesion numbers and sizes, varieties Indonesian, Roupi and Qi Men were categorized as resistant, varieties Jue King and P-5 as moderately resistant and varieties P1, P3 and Chuy as susceptible.

In general varieties with large and broad leaves were more susceptible to the grey blight disease than those with relatively shorter and smaller leaves. When artificially inoculated 
with Pestalotiopsis, leaves of three resistant varieties (Indonesian, Roupi and Qi Men) showed smaller lesions and lower number of lesions leaf ${ }^{-1}$ than those of susceptible varieties (P-3, Chuy and P-1), as shown in Table 1. These results were consistent with those reported elsewhere (Chen and Chen, 1982).

In this study, we showed that Pestalotiopsis infection caused significant damage to leaves on susceptible varieties but not on resistant varieties. The results showed that grey blight was found to be variety dependent. The grey blight disease caused more severe damage on P-1, P-3 and Chuy as compare to other varieties (Koh et al., 2001). This was confirmed from the results that artificial inoculation of the pathogen resulted in higher infection rate and more severe disease development on P-1, followed by Chuy, and P-3, as shown in Table 1.

Table 1: Reaction of different varieties to Pestalotiopsis and mean diameter lesions.

\begin{tabular}{|c|c|c|c|c|}
\hline Varieties & Reaction $^{\mathrm{a}}$ & $\begin{array}{l}\text { No. of plants } \\
\text { observed }\end{array}$ & $\begin{array}{l}\text { Lesion diameter } \\
(\mathrm{mm}): \quad \text { Mean } \\
\pm \mathrm{SD}\end{array}$ & $\begin{array}{l}\text { Number of } \\
\text { lesions leaf-1 }\end{array}$ \\
\hline Indonesian & $\mathrm{R}$ & 15 & $3.00 \pm 1.00 \mathrm{E}$ & $1.5 \pm 0.58 \mathrm{D}$ \\
\hline Roupi & $\mathrm{R}$ & 16 & $3.33 \pm 0.58 \mathrm{E}$ & $1.83 \pm 0.50 \mathrm{CD}$ \\
\hline Qi men & $\mathrm{R}$ & 14 & $4.00 \pm 1.00 \mathrm{DE}$ & $2.17 \pm 0.50 \mathrm{BCD}$ \\
\hline Jue King & M & 13 & $6.00 \pm 2.00 \mathrm{CD}$ & $2.33 \pm 0.29 \mathrm{BCD}$ \\
\hline P-5 & M & 21 & $7.00 \pm 1.00 \mathrm{C}$ & $2.83 \pm 1.00 \mathrm{ABC}$ \\
\hline P-3 & $\mathrm{S}$ & 18 & $11.67 \pm 2.52 \mathrm{~B}$ & $2.833 \pm 0.58 \mathrm{ABC}$ \\
\hline Chuy & $\mathrm{S}$ & 19 & $13.67 \pm 1.53 \mathrm{AB}$ & $3.00 \pm 0.29 \mathrm{AB}$ \\
\hline P-1 & $\mathrm{S}$ & 22 & $15.00 \pm 1.00 \mathrm{~A}$ & $3.833 \mathrm{~A}$ \\
\hline
\end{tabular}


Note: Data were statistically analysed and means were compared using LSD $P<0.05$ values. ${ }^{\text {a }}$ R, Resistant; M, Moderately Resistant; S, Susceptible. Means followed by same letters were not statically different.

Our results indicate that when Pestalotiopsis establishes infection inside the host tissue, it may produce toxic metabolites, which may alter plant physiology including photosynthesis, which significantly affect the leaf tissue in terms of leaf weight and plant yield (Senthil et al., 2010). Under disease condition plant activities such as water use efficiency, transpiration rate, and stomatal conductance is reduced which significantly affect plant health (Kumar et al., 2013).4.2

\subsection{Effect of Pestalotiopsis Infection on Tea Yield Parameters}

Pestalotiopsis has been reported to cause grey blight of tea in India, Japan and China (Chen et al., 2017; Joshi, Sanjay, Baby, and Mandal, 2009; Horikawa, 1986).

As shown above, Pestalotiopsis infection causes significant damage to tea leaves. To thoroughly characterize the damage caused by grey leaf blight in eight different varieties, we compared fresh leaf weight, dry leaf weight and number of leaves per plant of Pestalotiopsis-inoculated plants to non-inoculated plants. All varieties showed significant variation in these yield parameters.

Pathogen inoculation, varieties and inoculation $\mathrm{x}$ variety interaction had significant effect on fresh leaf weight. A comparison of varieties revealed maximum fresh leaf weight plant $^{-1}$ in varieties Indonesian (0.618 gm) and Roupi (0.600 gm), whereas minimum fresh leaf weight plant $^{-1}$ was observed in varieties P-1 (0.292 gm) and Chuy (0.265 gm) as shown in Table 2.

Table 2: Average values of different growth parameters of different tea varieties affected by Pestalotiopsis.

\begin{tabular}{|c|c|c|c|c|}
\hline Treatment & $\begin{array}{l}\text { No. of spots } \\
\text { per leaf }\end{array}$ & $\begin{array}{c}\text { Mean fresh } \\
\text { leaves } \\
\text { weight }\end{array}$ & $\begin{array}{l}\text { No of leaves } \\
\text { per plant }\end{array}$ & $\begin{array}{c}\text { Mean dry } \\
\text { leaves } \\
\text { weight }\end{array}$ \\
\hline Pathogen & & & & \\
\hline Non-inoculated & $0.00 \pm 0.0 \mathrm{~B}$ & $\begin{array}{l}0.46 \pm 0.03 \\
\text { A }\end{array}$ & $8.71 \pm 0.85 \mathrm{~A}$ & $0.26 \pm 0.02 \mathrm{~A}$ \\
\hline Inoculated & $5.08 \pm 1.46 \mathrm{~A}$ & $0.34 \pm 0.02$ & $6.38 \pm 0.74 \mathrm{~B}$ & $0.17 \pm 0.02 \mathrm{~B}$ \\
\hline
\end{tabular}




\begin{tabular}{|c|c|c|c|c|}
\hline & & B & & \\
\hline LSD & 0.1102 & 0.006 & 0.083 & 0.0014 \\
\hline \multicolumn{5}{|l|}{ Varieties } \\
\hline Indonesian & $1.50 \pm 0.5 \mathrm{D}$ & $\begin{array}{l}0.62 \pm 0.03 \\
\text { A }\end{array}$ & $\begin{array}{l}11.33 \pm 0.79 \\
\text { A }\end{array}$ & $0.28 \pm 0.02 \mathrm{~A}$ \\
\hline Roupi & $1.83 \pm 0.58 \mathrm{CD}$ & $\begin{array}{l}0.60 \pm 0.03 \\
\text { A }\end{array}$ & $9.50 \pm 0.58 \mathrm{~B}$ & $\begin{array}{l}0.27 \pm 0.02 \\
\mathrm{AB}\end{array}$ \\
\hline Jue King & $\begin{array}{l}2.33 \pm 0.29 \\
\text { BCD }\end{array}$ & $\begin{array}{l}0.41 \pm 0.03 \\
\text { B }\end{array}$ & $8.17 \pm 0.79 \mathrm{C}$ & $0.26 \pm 0.02 \mathrm{~B}$ \\
\hline P-5 & $\begin{array}{l}2.83 \pm 0.50 \\
\mathrm{ABC}\end{array}$ & $\begin{array}{l}0.38 \pm 0.04 \\
\text { В }\end{array}$ & $\begin{array}{l}6.00 \pm 0.79 \\
\mathrm{DE}\end{array}$ & $0.22 \pm 0.01 \mathrm{C}$ \\
\hline P-3 & $\begin{array}{l}2.83 \pm 0.58 \\
\mathrm{ABC}\end{array}$ & $\begin{array}{l}0.34 \pm 0.04 \\
\text { C }\end{array}$ & $5.50 \pm 0.58 \mathrm{E}$ & $\begin{array}{l}0.19 \pm 0.02 \\
\mathrm{D}\end{array}$ \\
\hline Qi man & $\begin{array}{l}2.17 \pm 0.29 \\
\mathrm{BCD}\end{array}$ & $\begin{array}{l}0.30 \pm 0.02 \\
\text { D }\end{array}$ & $7.83 \pm 0.79 \mathrm{C}$ & $\begin{array}{l}0.17 \pm 0.02 \\
\mathrm{DE}\end{array}$ \\
\hline Chuye & $3.00 \pm 0.50 \mathrm{AB}$ & $\begin{array}{l}0.27 \pm 0.02 \\
D\end{array}$ & $6.67 \pm 0.79 \mathrm{D}$ & $0.15 \pm 0.02 \mathrm{E}$ \\
\hline P-1 & $3.83 \pm 0.76 \mathrm{~A}$ & $0.29 \pm 0.03$ & $5.33 \pm 1.26 \mathrm{E}$ & $0.16 \pm 0.02 \mathrm{E}$ \\
\hline
\end{tabular}




\begin{tabular}{|l|l|l|l|l|}
\hline & & $\mathrm{D}$ & & \\
\hline LSD & 0.505 & 0.018 & 0.488 & 0.011 \\
\hline
\end{tabular}

Note: Means of three leaves per plant per replication were taken. Experiments were repeated three time with three biological replications. Data were statistically analysed and means were compared using LSD $P<0.05$ values.

Analysis of pathogen $\mathrm{x}$ variety interactions indicated that, when inoculated with pathogen, variety P-1 displayed least fresh weight plant $^{-1}(0.207 \mathrm{gm})$, whereas variety Indonesian displayed the greatest fresh weight plant $^{-1}(0.553 \mathrm{gm})$, as shown in Figure 2. In non-inoculated control treatments, maximum fresh weight plant ${ }^{-1}(0.683 \mathrm{gm})$ was observed in the Indonesian variety and minimum fresh weight $(0.310 \mathrm{gm})$ was recorded in the Chuy variety. Since tea is a leafy crop, any damage to leaf from Pestalotiopsis infection will result in quality and yield reduction (Pallavi et al., 2012).

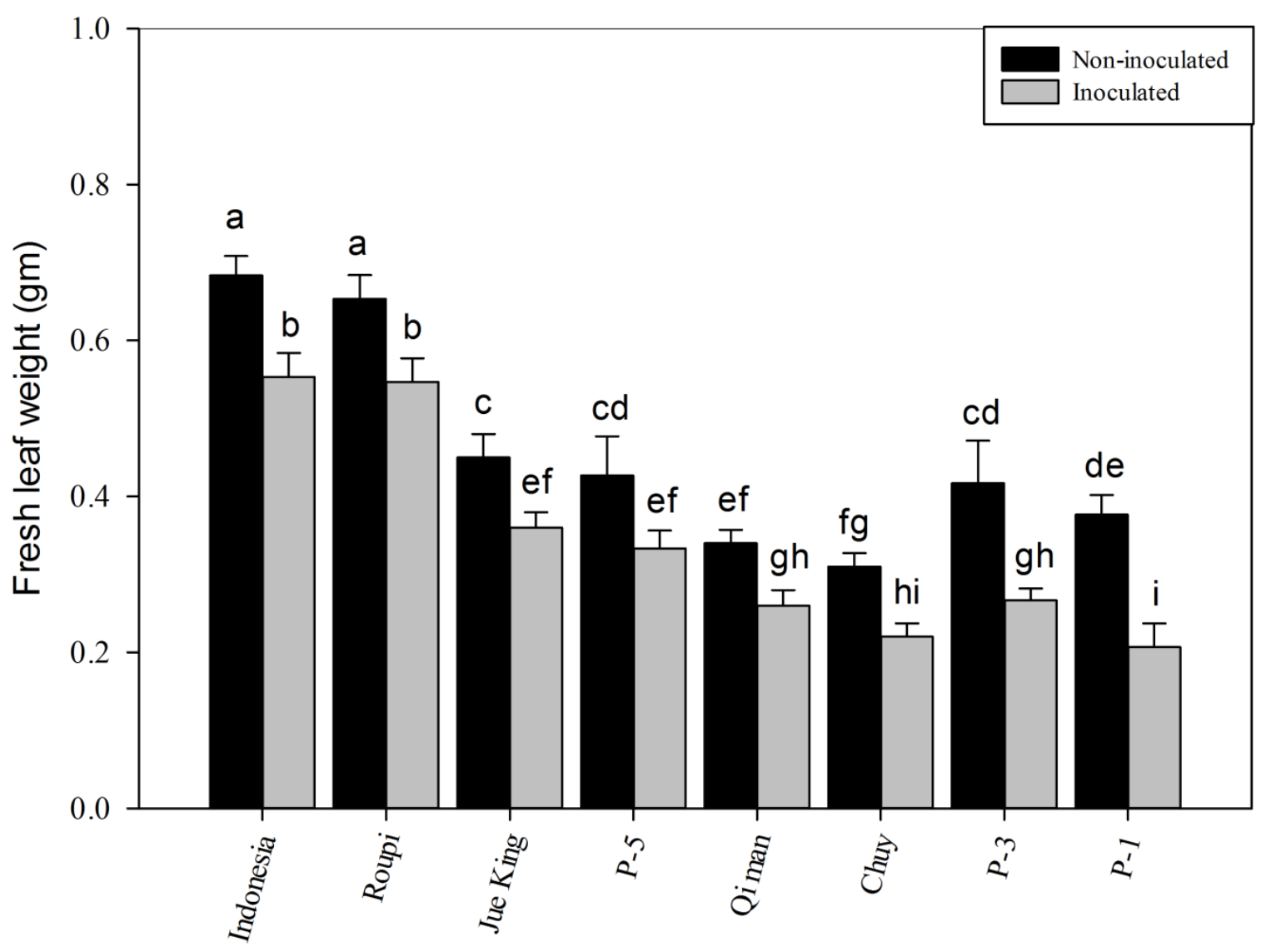

Figure 2: Interaction effect of pathogen inoculation and varieties on mean fresh leaf weight per plant $(n=4)$. Data were statistically analysed and the small alphabetical letters $(\mathrm{a}, \mathrm{b}, \mathrm{c} \ldots)$ above the mean bars show significant differences $(P<0.05)$ among treatments. 
Similarly, the number of leaves per plant was also significantly affected by pathogen inoculation. Maximum number of leaves per plant (8.71) was recorded in the control treatment, whereas minimum number of leaves per plant (6.38) was observed in the pathogen inoculated treatment. In the case of varieties, maximum number of leaves per plant (11.33) was observed in Indonesian variety, while minimum number of leaves per plant (5.33) was recorded in P-1 variety. In the case of interaction, least number of leaves per plant (4.00) was observed in the P-1 variety, while maximum number of leaves per plant (10.67) was observed in the Indonesian variety when inoculated with pathogen. In the case of non-inoculated treatment, maximum number of leaves per plant (12.00) was observed in the Indonesian variety, while minimum number of leaves per plant (6.67) was observed in the P-1 variety, as shown in Figure 3.

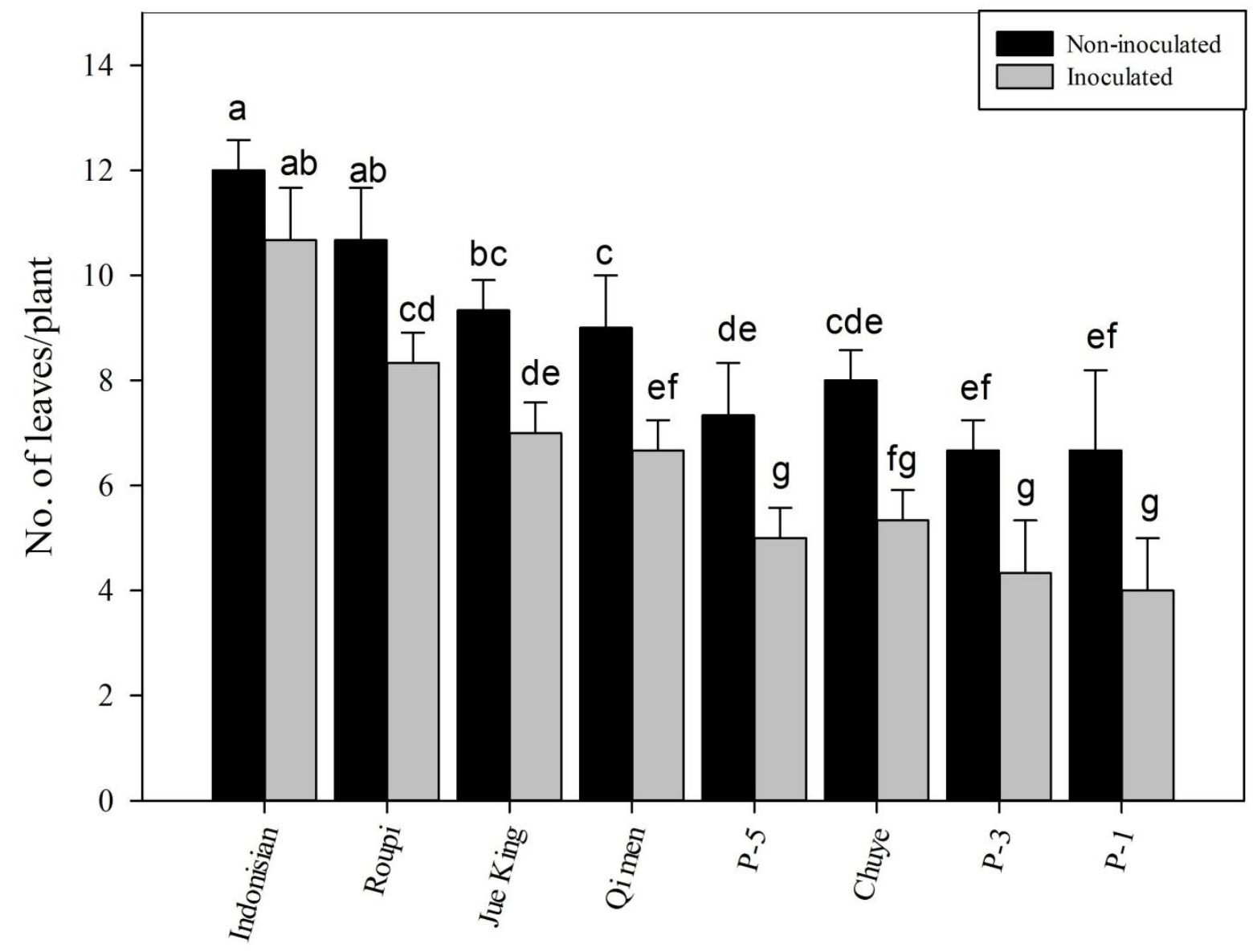

Figure 3: Interaction effect of pathogen inoculation and varieties on number leaves per plant.

Data were statistically analysed and letters $(a, b, c .$.$) above the mean bars show the$ significant differences $(P<0.05)$ among treatments. Each experiment was performed using three replications.

Similarly, Pestalotiopsis inoculation, varieties and their interaction showed significant effect on dry leaf weight plant ${ }^{-1}$ as shown in Table 2. In the case of pathogen inoculated plants, maximum dry leaf weight plant $^{-1}(0.278 \mathrm{gm})$ was recorded in the Indonesian variety, while minimum dry leaf weight plant $^{-1}(0.150 \mathrm{gm})$ was recorded in the Chuy variety. In the case of non-inoculated plants, maximum dry leaf weight plant $^{-1}(0.323 \mathrm{gm})$ was recorded in the 
Indonesian variety, while minimum dry leaf dry weight plant $^{-1}(0.220 \mathrm{gm})$ was recorded in the P-1 variety, as shown in Figure 4. Plant dry matter and biomass were significantly reduced in infected plants (Ponmurugan, Baby, and Rajkumar, 2007). This might be due to alterations in plant growth of the host and pathogen interaction (Igoe et al., 1995) and low dry matter due to the inefficient carbon assimilation (Micheal 1978).

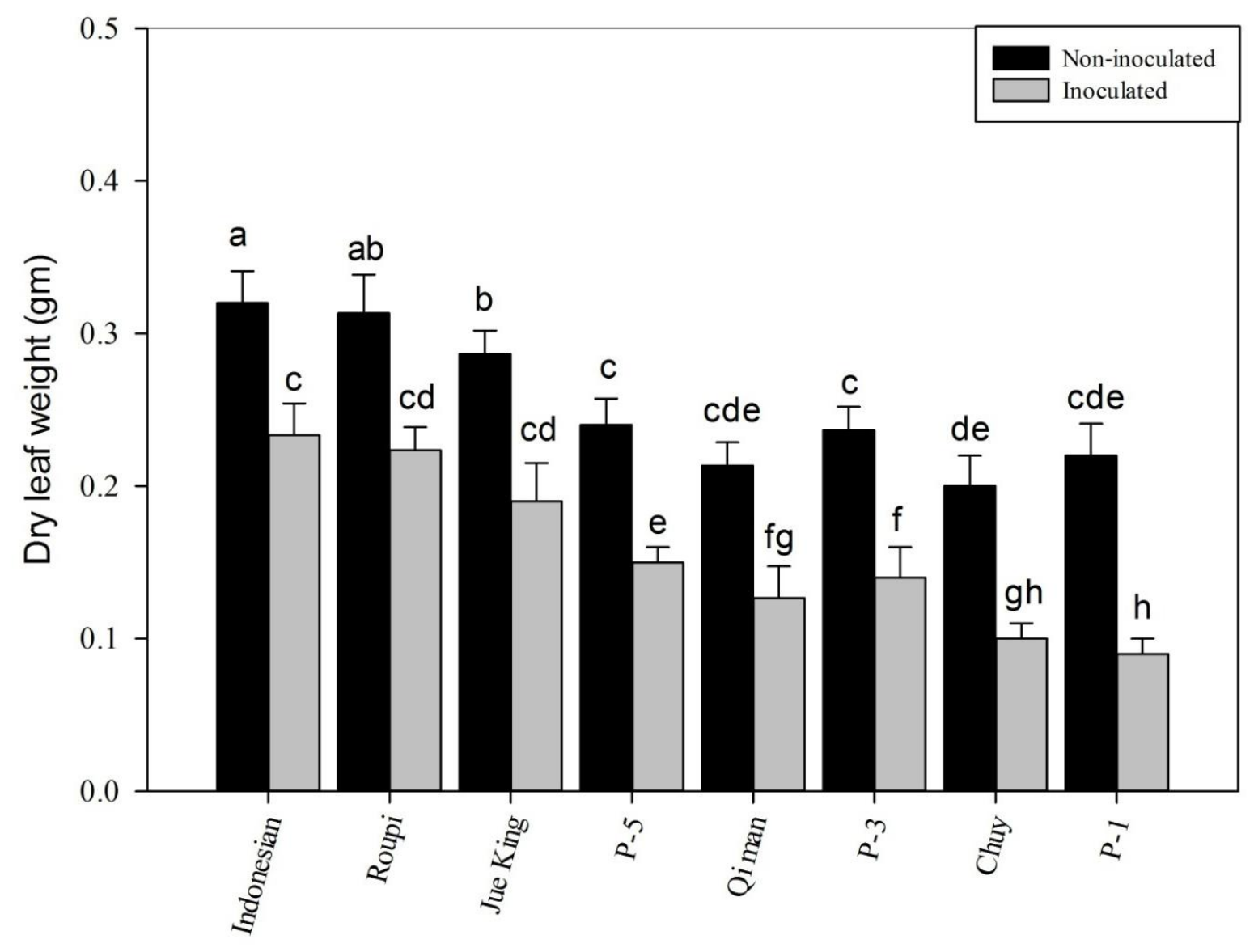

Figure 4: Interaction effect of pathogen inoculation and varieties on dry leaf weight. Data were statistically analysed and letters $(a, b, c \ldots)$ above the mean bars show significant differences $(P<0.05)$ among treatments. Each experiment was performed in three replications.

\section{Conclusions}

In the present study, we show the occurrence of grey leaf blight in Pakistan for the first time. We also showed that this disease is caused by Pestalotiopsis. Furthermore, in a screen of local and imported tea varieties against the pathogen, we identified several varieties with high resistance, which, we recommend to be used in the management of this disease.

\section{Acknowledgement}

This work was partially supported by funds to G.S.A. from the Florida Agriculture Experiment Station of the Institute of Food and Agricultural Sciences at the University of Florida (FLA-APO-005155), and Division of Sponsored Research (00108615). Additional support was provided by Higher Education Commission of Pakistan to A.A. 


\section{References}

Anandhan, A., Tamilselvam, K., Radhiga, T., Rao, S., \& Essa, M. M. (2012). Manivasagam, T. Theaflavin, a Black Tea Polyphenol, Protects Nigral Dopaminergic Neurons Against Chronic MPTP/Probenecid Induced Parkinson's Disease. Brain Research, 1433, 104-113.

https://doi.org/10.1016/j.brainres.2011.11.021

Ashigai, H., Taniguchi, Y., Suzuki, M., Ikeshima, E., Kanaya, T., Zembutsu, K., Tomita, S., Miyake, M., \& Fukuhara, I. (2016). Fecal Lipid Excretion After Consumption of A Black Tea Polyphenol Containing Beverage. Biological \& Pharmaceutical Bulletin, 39(5), 699-704.

https://doi.org/10.1248/bpb.b15-00662

Chen, Z., \& Zhu, C. (2011). Modelling inactivation by aqueous chlorine dioxide of Dothiorella gregaria Sacc. and Fusarium tricinctum (Corda) Sacc. Spores inoculated on fresh chestnut kernel. Letters in applied microbiology, 52(6), 676-68.

https://doi.org/10.1111/j.1472-765X.2011.03061.x

Chen, Y. J., Zeng, L., Shu, N., Wang, H., \& Tong, H. R. (2017). First Report of Pestalotiopsis camelliae causing Grey Blight Disease on Camellia sinensis in China. Plant Disease, 101(6), 1034-1034. doi:10.1094/PDIS-01-17-0033-PDNChen, T. \& Chen, S. (1982). Disease of Tea and Their Control in the People's Republic of China. Plant Disease, 66, 961-965.

Fatima, M., \& Rizvi, S. I. (2015). Anti Oxidative Effect of Black Tea Theaflavin on Erythrocytes Subjected to Oxidative Stress. National Academy Science Letters, 38(1), 25-28. https://doi.org/10.1007/s40009-014-0285-9

Food and Agriculture Organization of the United Nations, Committee on Commodity Problems, Intergovernmental Group on Tea. (2015). World tea production and trade: Current and future development (I4480E/1/03.15). Retrieved from http://www.fao.org/3/a-i4480e.pdf

Horikawa, T. (1986). Yield Loss of New Tea Shoots Due to Grey Blight Caused by Pestalotia longiseta Spegazzini. Bulletin of the Shizuoka Tea Experimental Station, 12, $1-8$.

Joshi, S. D., Sanjay, R., Baby, U. I. \& Mandal, A. K. A. (2009). Molecular Characterization of Pestalotiopsis spp. Associated with Tea (Camellia sinensis) in Southern India Using RAPD and ISSRMmarkers. Indian Journal of Biotechnoly, 8(4), 377-383.Keith, 1., Ko, W. H., \& D.M., S. (2006). Identification Guide for Diseases of Tea (Camellia sinensis). Plant Disease, 33, 1-4.

Koh, Y. J., Shin, G. \& Hun, G. (2001). Seasonal Occurrence of Development of Grey Blight of Tea Plants in Korea. Plant Pathology, 17(1), 40-44.

Lee, W., Min, W. K., Chun, S., Lee, Y. W., Park, H., Lee, D. H., Lee, Y. K., \& Son, J. E. (2005). Long-term Effects of Green Tea Ingestion on Atherosclerotic Biological Markers in Smokers. Clinical Biochemistry, 38(1), 84-87.

https://doi.org/10.1016/j.clinbiochem.2004.09.024

Keith, 1., Ko, W. H., \& D.M., S. (2006). Identification Guide for Diseases of Tea (Camellia 


\section{Macrothink}

sinensis). Plant Disease, 33, 1-4. Maharachchikumbura, S. N. N., Chukeatirote, E., Guo, L., Crous, P. W., Mckenzie E. H. C. \& Hyde K. D. (2013). Pestalotiopsis Species Associated with Camellia sinensis (tea). Mycotaxon, 123, 47-61.

Mandel, S. A., Amit, T., Weinreb, O., Reznichenko, L., \& Youdim, M. B. H. (2008). Simultaneous Manipulation of Multiple Brain Targets by Green Tea Catechins: A Potential Neuroprotective Strategy for Alzheimer and Parkinson Diseases. CNS Neuroscience \& Therapeutics, 14(4), 352-365. https://doi.org/10.1111/j.1755-5949.2008.00060.x

Ponmurugan, P., Baby, U. I. and Rajkumar, R. (2007). Growth, Photosynthetic and Biochemical Responses of Tea Cultivars Infected with Various Diseases. Photosynthetica, 45(1), 143-146. https://doi.org/10.1007/s11099-007-0023-3

Rietveld, A., \& Wiseman, S. (2003). Antioxidant Effects of Tea: Evidence from Human Clinical Trials. Journal of Nutrition, 133(10), 3285S-3292S.

Takeda, Y. (2002). Genetic Analysis of Tea Grey Blight Resistance in Tea Plants. Japan Agricultural Research Quarterly, 36(3), 143-150. https://doi.org/10.6090/jarq.36.143

Wang, Y. C., \& Bachrach, U. (2002). The Specific Anti-Cancer Activity of Green Tea (-)-Epigallocatechin-3-Gallate (EGCG). Amino Acids, 22(2), 131-143.

https://doi.org/10.1007/s007260200002

Zhang, G., Wang, Y., Zhang, Y., Wan, X., Li, J., Liu, K., Wang, F., Liu, K., Liu, Q., \& Yang, C. (2012). Anti-Cancer Activities of Tea Epigallocatechin-3-Gallate in Breast Cancer Patients Under Radiotherapy. Current Molecular Medicine, 12, 163-176.

https://doi.org/10.2174/156652412798889063

Zhong, L., Furne, J. K., \& Levitt, M. D. (2006). An Extract of Black, Green, and Mulberry Teas Causes Malabsorption of Carbohydrate But Not of Triacylglycerol in Healthy Volunteers. American Journal of Clinical Nutrition, 84(3), 551-555.

\section{Copyright Disclaimer}

Copyright for this article is retained by the author(s), with first publication rights granted to the journal.

This is an open-access article distributed under the terms and conditions of the Creative Commons Attribution license (http://creativecommons.org/licenses/by/4.0/). 